\title{
A IMPRENSA FEMININA E A EMANCIPAÇÃO DA MULHER: UMA ANÁLISE DO PERIÓDICO O SEXO FEMININO(RIO DE JANEIRO - 1889)
}

\section{Karen Menegatt*}

DOI: 10.11606/issn.2318-8855.v9i1p56-82

Resumo: O tema que orienta essa pesquisa é a concepção de mulher e os discursos sobre o universo feminino na imprensa brasileira em 1889, partindo da problematização que busca entender quais eram as narrativas sobre o lugar da mulher e suas relações nas vésperas da Proclamação da República no Brasil, a partir da análise do periódico $O$ Sexo Feminino. A partir desse trabalho, objetiva-se analisar e compreender a atuação da imprensa feminina durante o final do Império no Brasil, investigar os discursos sobre o ser mulher e suas possibilidades, bem como analisar as principais reivindicações presentes no periódico. Para isso, a metodologia utilizada foi a de análise documental e de revisão bibliográfica baseada em autoras como Simone de Beauvoir (2016), Cecília Vieira do Nascimento (2004), Michelle Perrot (1998, 2006), Céli Pinto (2003), Norma Teles (2004), Constância Lima Duarte (2017, 2019), entre outras e outros. Ao longo da pesquisa pode-se constatar que as principais reivindicações femininas giravam em torno da educação e do acesso ao universo do trabalho, que levariam a emancipação racional da mulher, baseando-se na defesa da igualdade dos sexos.

Palavras-chave: Brasil Império, História da Imprensa, História das Mulheres.

* Graduanda em História na UFFS. E-mail para contato: karenmenegatt@outlook.com. 


\section{artigos}

\section{A IMPRENSA FEMININA E A EMANCIPAÇÃO DA MULHER: UMA ANÁLISE DO PERIÓDICO O SEXO FEMININO(RIO DE JANEIRO - 1889}

A condição social da mulher marca exatamente o grau de civilização de um povo, e é o reflexo do lar doméstico, porque a família é a molécula social; onde a mulher é rainha, a sociedade é culta, onde a mulher é escrava, é bárbara a sociedade. (O SEXO FEMININO, n² 2, 1889, p. 01) ${ }^{1}$

\section{INTRODUÇÃO}

A partir do conjunto de renovações historiográficas das últimas décadas, passou-se a compreender a imprensa como importante ferramenta analítica, na medida em que ela foi (e é) um espaço privilegiado de debates políticos, sociais e culturais e catalizador de transformações da realidade. Muitos foram os temas que circularam pelos periódicos do século XIX desde o surgimento da imprensa no Brasil em 1808, com a chegada da Família Real (MACHADO, 2010, p. 36). Entretanto, foi preciso esperar quase meio século para que as mulheres começassem a fazerem-se ouvidas como redatoras em periódicos femininos. Para definir o que é imprensa feminina, aproprio-me da descrição de Buitoni sobre a questão: "Imprensa feminina é um conceito definitivamente sexuado: o sexo de seu público faz parte de sua natureza (...)" (BUITONI, 1990, p.7), ou seja, independente de quem escreve, o público alvo são as mulheres. Nesta mesma esfera, existe também a imprensa feminista, esta "destinada ao mesmo público, se diferenciará por protestar conta a opressão e a discriminação e exigirá a ampliação de direitos civis e políticos." (DUARTE, 2017, p. 14).

Dito isso, o tema o tema central deste artigo são os discursos sobre o universo feminino na imprensa brasileira em 1889 produzidos por mulheres. Isso porque, busco examinar e problematizar as narrativas produzidas sobre a posição social das mulheres

\footnotetext{
${ }^{1}$ Ao citar as fontes, como o periódico e a Constituição, optei pela atualização da gramática.
} 


\section{artigos}

Karen Menegatt

às vésperas da Proclamação da República no Brasil, bem como as concepções femininas do "ser mulher" que circularam pelo periódico O Sexo Feminino, instalado no Rio de Janeiro, centro político administrativo do país durante o século XIX. Ademais, busco analisar suas principais reivindicações e as conexões com outros discursos coetâneos.

Ao longo da História, as mulheres foram silenciadas, ou ainda, como diz Michelle Perrot (2006), excluídas. Desvendar e conhecer suas narrativas, sobretudo as escritas por mãos femininas, é romper com esses silêncios e demonstrar a complexidade da História. A história da luta feminina por direitos através da imprensa ainda se mostra um vasto e rico campo a ser explorado no Brasil. Conhecer os discursos debatidos e construídos sobre o "ser mulher", a partir da escrita feminina, é compreender de que forma as mulheres daquele período reconheciam-se, quais eram suas reivindicações e divergências. Para isso, o artigo fundamenta-se em autoras que dialogam com a História das Mulheres e da Imprensa, como Simone de Beauvoir (2016), Cecília Vieira do Nascimento (2004), Michelle Perrot (1998, 2006), Céli Pinto (2003), Norma Teles (2004), Constância Lima Duarte (2017, 2019), entre outras e outros.

O artigo divide-se em seis seções, sendo a primeira a introdução. Na segunda seção, intitulada "Do privado ao público: a conquista de um espaço social", busco compreender como as esferas pública e privada eram compreendidas e manejadas, bem como a maneira com que as mulheres ocuparam esses espaços durante o período de análise do artigo. Na terceira seção, chamada "Imprensa das Mulheres", busco fazer um breve panorama sobre a imprensa feminina, seu surgimento e sua relevância à época. Na quarta seção, intitulada "O Sexo Feminino em palavras", descrevo as características do periódico analisado no artigo, trazendo informações sobre ele. A quinta seção denominada "Narrativas e discursos por mãos femininas", conta com a análise do periódico e 


\section{artigos}

\section{A IMPRENSA FEMININA E A EMANCIPAÇÃO DA MULHER: UMA ANÁLISE DO PERIÓDICO O SEXO FEMININO(RIO DE JANEIRO - 1889}

a construção dos discursos produzidos por suas redatoras. A sexta e última seção é reservada as considerações finais do trabalho.

\section{DO PRIVADO AO PÚBLICO: A CONSQUISTA DE UM ESPAÇO SOCIAL}

As diferenciações entre o espaço público e o espaço privado nem sempre foram as mesmas, haja visto serem fruto de transformações sociais e de significações de determinado processo histórico. As fronteiras que definem o público e o privado são constituídas basicamente por uma construção social que busca dar espaço, forma e função para cada indivíduo. A história da vida privada nem sempre foi alvo dos estudos historiográficos. É apenas com o interesse de certos autores e autoras pela história cultural que esta categoria de análise vai ganhando seu espaço na historiografia. A demarcação de uma esfera pública e de uma esfera privada, durante o final do século XVIII e início do século XIX, foi um fator determinante para a inserção e fixação da mulher em um espaço "destinado" a sua ocupação, espaço esse que acabou por invisibilizá-la da História.

Com as grandes transformações desencadeadas pelas Revoluções Francesa e Industrial, os conceitos de "privado" e "público" foram dramaticamente alterados e ressignificados a partir de marcas de gênero, raça e classe, que também ganhavam novos contornos no século XIX. A vida pública ficou destinada ao Estado, às questões de trabalho, de produção e de política; e, portanto, de pertencimento ao homem. Já a vida privada, que consistia basicamente nos cuidados da casa, da família e da reprodução, ficavam a cargo das mulheres, já que mais frágeis, possuíam um talento natural para a esfera doméstica 


\section{artigos}

\section{Karen Menegatt}

Embora a proposta ética do liberalismo seja a igualdade entre todos os indivíduos, as mulheres foram naturalizadas ideologicamente como seres que deveriam atuar na esfera doméstica, voltada a intimidade, a afetividade, aos cuidados e a reprodução. Desta maneira, conforme ressalta Michelle Perrot (1995) o industrialismo capitalista fortaleceu a divisão entre produção e reprodução, situando a mulher especificamente na esfera doméstica que estabeleceu a figura da "dona-de-casa", encarregada da vida privada. O movimento deste período levou ao retraimento das mulheres em relação ao espaço público e à constituição de um espaço privado familiar predominantemente feminino. (NOVAES, 2015, p. 5)

A divisão da sociedade por lugares de produção e consumo colocou o homem na fábrica e as mulheres no lar. Essa separação tinha o amparo de um discurso biológico que situava a mulher na esfera da reprodução, do íntimo, dos sentimentos, dos cuidados e do privado; e o homem, na esfera da razão, da inteligência e da força. Portanto, na análise aqui proposta, podemos definir público como o espaço das produções e da política - masculino, e privado como o espaço doméstico - feminino. Essas divisões buscam justificar a invisibilidade feminina na construção histórica, já que, quem durante muito tempo estava produzindo, criando e revolucionando eram os homens, enquanto mulheres pertencentes a classes privilegiadas tinham sua participação na sociedade e na vida pública reduzidas. ${ }^{2}$ Se até às vésperas da Revolução Francesa e da Revolução Industrial, essa divisão entre público e privado não considerava o gênero um fator determinante para a organização da sociedade, a História nos mostra que os conceitos e os lugares sociais de cada indivíduo são passíveis de transformações e ressignificações para atenderem as mudanças de contexto. Com esta nova construção e divisão de papeis, cabia então a mulher os cuidados domésticos, o que resultou no conceito de "muIher do lar", que passou a ser tratado como uma profissão, porém, esta não contava com remuneração e era bastante desvalorizada no meio social. Ao sexo feminino era

\footnotetext{
2 É importante ressaltar o que Michelle Perrot nos mostra em "Os excluídos da História" - mulheres pobres sempre circularam pelas ruas e trabalharam. A questão de participação no mercado de trabalho diz respeito às mulheres de classes mais abastadas. Porém, a privação de educação e de participação em certas camadas da sociedade relaciona-se à todas as mulheres.
} 


\section{artigos}

\section{A IMPRENSA FEMININA E A EMANCIPAÇÃO DA MULHER: UMA ANÁLISE DO PERIÓDICO O SEXO FEMININO(RIO DE JANEIRO - 1889}

destinado a educação dos filhos, os bons costumes, ser uma boa mãe e uma boa protetora da casa, como nos mostra as redatoras do periódico em seus textos sobre a atuação das mulheres na sociedade.

A literatura, os jornais e as revistas tiveram uma importante função na transformação dessa divisão e na reivindicação feminina pelo espaço público, o qual deveria fazer parte de seu universo também. A leitura, que por muito tempo foi uma atividade pública e de acesso a poucos, no final do século XIX, ainda muito restrita, já alcançava um público mais considerável, e diferentemente de antes, agora era uma atividade do âmbito privado. As mulheres pertencentes à elite econômica, tornaram-se as grandes leitoras da época, e viram na literatura e na escrita uma forma de luta e organização. Encontrar nas atividades privadas uma forma de conquistar e participar da vida pública foi uma das artimanhas femininas de grande importância para a representação feminina na sociedade e para a conquista de direitos, como nos mostra Michelle Perrot (1998).

Além de serem as grandes protagonistas das histórias lidas por si mesmas, o ato revolucionário de começar a também escrever, traçou uma rede de sociabilidade feminina, na qual as mulheres passaram a enxergar-se não apenas protagonistas das narrativas literárias, mas também de suas próprias histórias e de uma sociedade em construção. De acordo com Constância Lima Duarte (2017), a leitura (e por sua vez, a escrita), deram às mulheres consciência do lugar de exceção que ocupavam na sociedade e “(...) da condição subalterna a que o sexo estava submetido, e proporcionou o surgimento de escritos reflexivos e engajados (...)" (DUARTE, 2017, p. 14). É nesse contexto que surgem jornais escritos por mulheres, que contribuem de forma bastante significativa para 


\section{artigos}

Karen Menegatt

a apropriação feminina da esfera pública, tornando-se além de "rainhas do lar", protagonistas sociais de transformação de suas próprias realidades. Norma Teles, em seu texto Rebeldes, Escritoras, Abolicionistas, diz que "O ato de escrever implica numa revisão do processo de socialização assim como das representações conscientes; implica também em um enfrentamento do inconsciente invadido pela situação objetiva de dependência do homem." (TELES, 1989, p. 75). Os jornais escritos por mulheres traduzem essa "revisão do processo de socialização", dando passagem para que as mulheres ocupem espaços reservados apenas para as figuras masculinas e para que revolucionem os modos de socialização vigentes.

\section{IMPRENSA DAS MULHERES}

Um dos debates mais latentes no século XIX versou sobre o lugar da mulher na sociedade, a divisão dos sexos, bem como suas funções na comunidade. De acordo com Michelle Perrot (2006), apoiado em um discurso naturalista, o oitocentos explicava a divisão dos sexos baseado na existência de duas "espécies" (a feminina e a masculina), com qualidades e aptidões diferentes, o que acarretava a cada espécie uma função, ao homem cabia o trabalho e a vida pública, a mulher cabia os cuidados do lar, os tecidos e a costura. Em Os excluídos da História, Perrot está se referindo à sociedade francesa, porém, feito os devidos ajustes e adaptações, essa análise pode ser pertinente à realidade do Brasil imperial, como veremos nos relatos do periódico que pretendo analisar no decorrer do artigo.

Embaladas por um sentimento de mudança nesta forma de estrutura social e de reivindicações por direitos, a imprensa feminina surgiu timidamente no Brasil como um veículo de transformação de costumes e de difusão das ideias femininas, bem como a organização dessas ideias e de grupos de mulheres que estavam dispostas a 


\section{artigos}

\section{A IMPRENSA FEMININA E A EMANCIPAÇÃO DA MULHER: UMA ANÁLISE DO PERIÓDICO O SEXO FEMININO(RIO DE JANEIRO - 1889}

lutar de forma pública por seus direitos. Conforme Céli Pinto (2005), a imprensa produzida por mulheres manifesta-se como forma de buscar a liberdade em uma sociedade na qual os grupos excluídos começam a se organizar utilizando a escrita como forma de atuação. Norma Teles (2004) afirma que a conquista do território da escrita no Brasil foi difícil para as mulheres, a escrita feminina surge sobretudo, como um dispositivo que se dispunha a abrir caminhos para as reivindicações das mulheres, criando assim uma rede de sociabilidade entre o sexo feminino ou, como sugere Constância Lima Duarte (2019), para a criação da identidade feminina.

No Brasil, as primeiras publicações da imprensa feminina tratavam quase que exclusivamente de assuntos recreativos, os assuntos como política, literatura e cultura foram ganhando relevo com o passar dos anos. De acordo com Céli Pinto (2003), essas publicações eram ainda bastante efêmeras, e foi apenas na década de 1850 que surgiu o primeiro periódico feminino escrito por uma mulher considerada jornalista, o Jornal das Senhoras. O surgimento de uma imprensa feminina possibilitou às suas leitoras um veículo que buscava alertar as mulheres sobre sua condição e sobre a importância de reivindicarem direitos como a educação e o acesso ao universo do trabalho. A imprensa feminina contribui para "a existência de um incipiente movimento de construção de espaços públicos na sociedade brasileira, e no caso, por parte de pessoas que estavam completamente excluídas do campo da política e das atividades públicas." (PINTO, 2003, p. 33).

Excluídas da história, as mulheres encontram na imprensa um importante porta voz para a intervenção na dinâmica social. Para Muzart (2003), a criação de periódicos femininos surge da necessidade das mulheres conquistarem direitos: “Em primeiro lugar, 


\section{artigos}

Karen Menegatt

o direito à educação; em segundo, o direito à profissão e, bem mais tarde, o direito ao voto." (MUZART, 2003, p. 03). O direito à educação aparece constantemente como forma de emancipação feminina e melhor condução do lar, pois, de acordo com Perrot (2006), a mãe possuía a função educadora de seus filhos. Caberia apenas às mulheres, a partir da noção compulsória de maternidade, a condução dos destinos do gênero humano e, para isso, a educação era um instrumento fundamental.

Uma das principais reivindicações das mulheres era o direto a ter educação formal e entrar no mercado de trabalho. Conforme Teles (2004), embora muitas das campanhas em prol dessas bandeiras aparecessem "ligadas ao reforço do papel de mãe, de boa esposa, de dona de casa", essas reivindicações eram valiosas e importantes para "enaltecer o papel da mulher tanto dentro quanto fora de casa" (TELES, 2004, p. 357). Isso porque, parecia de fundamental importância conquistar o apoio de homens e muIheres que acreditavam no papel exclusivo de "rainha do lar" atribuído ao sexo feminino. Essa postura pode ser compreendida como uma inovação na forma de produzir memória sobre o universo feminino e suas possibilidades para além da esfera doméstica e da opressão masculina. Compreendemos a participação das mulheres na construção dos periódicos como uma expressão de resistência a um conjunto de opressões, do mesmo modo que pode ser lido como indício de como a imprensa era um importante condutor de mudanças na sociedade e de participação da esfera pública. 0 campo jornalístico, como um campo de luta, contribuiu de forma impactante para a resistência feminina e construção de uma identidade de reivindicações e de reconhecimento do sexo feminino, principalmente a partir da segunda metade do século XIX.

\section{O SEXO FEMININO EM PALAVRAS}




\section{artigos}

\section{A IMPRENSA FEMININA E A EMANCIPAÇÃO DA MULHER: UMA ANÁLISE DO PERIÓDICO O SEXO FEMININO(RIO DE JANEIRO - 1889}

O Segundo Reinado (1840-1889) é conhecido entre as pesquisadoras e os pesquisadores da História da Imprensa como o período de maior liberdade da imprensa e, é nesse contexto, em 1852, que surge o primeiro jornal feminino, O Jornal das Senho$\operatorname{ras}^{3}$, fundado por sua proprietária, Joana Paula Manso de Noronha. Este era editado e escrito por mulheres, com conteúdo direcionado a outras mulheres. Vinte um anos depois, em 1873, em Campanha (MG), surgiria pela primeira vez o periódico intitulado $O$ Sexo Feminino, objeto de análise neste artigo. Dirigido por D. Francisca Senhorinha da Motta Diniz ${ }^{4}$, com a colaboração de suas filhas e diversas senhoras ${ }^{5}$, o periódico era publicado semanalmente e "especialmente dedicado aos interesses da mulher", como consta em suas capas. Em seu primeiro ano de atuação, o periódico obteve uma quantidade bastante expressiva de publicações

Sua tiragem alcançava média de 800 exemplares e, após os dez primeiros números do semanário, foram reimpressos outros 4000 . Uma quantidade significativa para o período, sobretudo se considerarmos o número de leitores e

\footnotetext{
${ }^{3}$ O Jornal das Senhoras foi fundado em 1852 no Rio de Janeiro por Joana Paula Manso de Noronha e era publicado sempre aos domingos. Em sua capa consta que o periódico pretendia tratar de "Modas, Literatura, Belas Artes e Teatro. O jornal manteve-se em circulação até o ano de 1855.

${ }^{4}$ De acordo com Constância Lima Duarte (2017), Francisca Senhorinha da Motta Diniz nasceu em São João Del-Rei (MG) em data desconhecida, assim como a de sua morte. Foi casada com José Joaquim da Silva Diniz, proprietário do periódico e da tipografia O Monarchista, José Diniz era também professor. Fundou ainda outros jornais, como A Primavera (1880) e A Voz da Verdade (1880), e foi autora do romance A Judia Rachel, juntamente com sua filha Elisa Diniz. Foi professora, defendendo arduamente a educação ao alcance das mulheres. Fundou o Liceu Santa Izabel e a Escola Doméstica (1890) no Rio de Janeiro, estas que tinham como objetivo oferecer o ensino secundário às jovens meninas. D. Francisca Senhorinha foi uma grande voz do movimento de escrita feminina e uma grande pugnadora dos direitos das mulheres e do acesso à educação para as mulheres.

${ }^{5}$ Algumas colaboradoras: Ernestina Fagundes Varela, Cândida A. dos Santos, Laura Eulina G., Luiz E. Pereira, Maria Leonilda Carneiro de Mendonça, I. de B. Leite, Ignez Flacia d'Aguiar Mourão, Marcolina Higgis, Maria Deraisme, Maria Cândida M. de Vasconcellos, Maria Joaquina de Mesquita e Rocha, Leopoldina de J. Paes Mamede, Anna Maria Ribeiro de Sá, Marianna C. de Arantes, Maria Peregrina de Souza, Palmyra de Abreu, Eulália Diniz e Josefa Esteves de G. Del Canto. (DUARTE, 2017, p. 190).
} 


\section{artigos}

\section{Karen Menegatt}

leitoras em potencial, assim como o da população de Campanha. De uma população total de 20.071 pessoas em Campanha, apenas 1.458 mulheres sabiam ler e escrever em 1872, ou seja, cerca de $7 \%$ da população total, número um pouco superior à diminuta média nacional, que era de $5,5 \%$ do total da população, segundo dados do Recenseamento daquele ano. O Sexo Feminino atingia, provavelmente, uma razoável porcentagem da população feminina local alfabetizada, assim como um público fora dos limites da cidade. (NASCIMENTO, 2004, p. 21)

Após um ano de considerável desempenho na cidade de Campanha, D. Francisca Senhorinha muda-se para o Rio de Janeiro, lugar que passaria a ser a nova sede do periódico. Depois de uma pausa em suas publicações ${ }^{6}$, em 1889, ano de grandes transformações políticas e sociais no Império, O Sexo Feminino continua na cena carioca defendendo os interesses femininos, bem como a emancipação da mulher. São essas edições do periódico que pretendo analisar no decorrer desse trabalho. ${ }^{7}$

A redação do jornal localizava-se na Rua do Lavradio, número 101. No ano de 1889 foram publicadas 10 edições do periódico, cada edição era organizada em quatro páginas que contava com artigos fixos como "A racional emancipação da mulher" e "O casamento", e outros, que variavam de edição para edição, como por exemplo, as novelas, poemas, adivinhações, charadas, receitas, contos, e pensamentos sobre a mulher. O Sexo Feminino foi um dos primeiros veículos públicos da imprensa brasileira (dirigido e escrito inteiramente por mulheres), a debater e posicionar-se pelos direitos femininos

\footnotetext{
${ }^{6}$ O periódico teve sua primeira publicação no ano de 1873 em Campanha (MG), em 1875 mudou-se para o Rio de Janeiro, onde atuou por mais dois anos e, em 1877 deu uma pausa em suas publicações. Em 1880 D. Francisca Senhorinha publica a revista semanal Primavera, em 1889 retoma as publicações do periódico O Sexo Feminino, ainda com o mesmo propósito de emancipação da mulher. Com a proclamação da República em 15 de novembro de 1889, Francisca Senhorinha imediatamente troca o nome do jornal para O Quinze de Novembro do Sexo Feminino, o que nos remete a ideia de que o evento viria a dar novas expectativas e novo ânimo às lutas e reivindicações femininas. 7

Durante este período havia a circulação de outros periódicos por todo o Império do Brasil que debatiam assuntos semelhantes, como é o caso do jornal A Família, de Josephina Alvarez de Azevedo. Fundado em São Paulo em 1888, foi transferido para o Rio de Janeiro em 1889 e circulou até o ano 1897. O jornal se destaca pelo tom combativo em defesa da emancipação da mulher e contra a tutela masculina.
} 


\section{artigos}

\section{A IMPRENSA FEMININA E A EMANCIPAÇÃO DA MULHER: UMA ANÁLISE DO PERIÓDICO O SEXO FEMININO(RIO DE JANEIRO - 1889}

e, em decorrência disso, por seu considerável alcance, pode ser visto como um notável agente catalizador de mudanças sociais (FERREIRA, 2010).

A edição número 04, de 1875, nos traz a informação que a existência do periódico chegou ao conhecimento do Imperador Dom Pedro II que solicitou à redatora, Francisca Senhorinha, um exemplar. A jornalista recebeu e publicou o evento com satisfação e orgulho. Na edição seguinte, as leitoras foram informadas que tanto Dom Pedro quanto sua filha, a Princesa Isabel, passaram a ser assinantes do periódico. As reivindicações e os textos do Sexo Feminino estavam ao alcance de dois membros da Família Real.

Podemos notar que Francisca Senhorinha mantinha o jornal a partir das assinaturas de suas leitoras e com os anúncios que publicava na última página do periódico. Esses anúncios eram geralmente de escolas e professoras particulares, mas contava também com propagandas de lojas, sapateiros, gabinetes dentários, armarinhos, tipografias, papelarias, fotografias, entre outros. Eram recorrentes os pedidos para que as senhoras de toda a Corte, e também de fora dela, assinassem o periódico e o divulgasse a fim de manter a folha circulando. Havia também pedidos para que as assinaturas fossem pagas em dia.

O periódico fazia uso de uma linguagem acessível para que atingisse "todos os tipos de mulheres", desde bordadeiras até as damas da alta sociedade. A retórica é utilizada de forma a criar uma mulher universal, a qual todas pudessem se identificar e compartilhar anseios, vontades, deveres, direitos e reivindicações, e que dessa forma iria criar nas leitoras do periódico, uma consciência de sua condição e do ser mulher na sociedade brasileira. 


\section{artigos}

Karen Menegatt

\section{1. “A augusta família imperial Brasileira, O Sexo Feminino, felicita com pro- fundo amor e respeito" 8}

O corajoso discurso moderno, progressista e igualitário do periódico pode levar seus atuais leitores a deduzirem um profundo vínculo do jornal e de suas redatoras aos ideias republicanos tão debatidos e presentes no contexto histórico no qual o periódico estava inserido. Porém, uma análise mais profunda e atenta mostra-nos que, pelo menos até a data da Proclamação da República, suas identificações políticas, bem como de suas contribuintes, eram bastante dúbias e oscilantes. Por isso mapear o viés político do periódico é uma missão que pressupõe não só a análise cuidadosa dos textos, mas também de seus associados e de seus parceiros no mundo intelectual da corte.

A primeira instalação de $O$ Sexo Feminino localizava-se na tipografia que pertencia ao marido de D. Francisca Senhorinha, que também era dono e redator do jornal $O$ Monarchista, título que já sugere uma posição política bastante marcada. Além do contato direto com um correspondente dos ideais monarquistas, O Sexo Feminino possuía um histórico de desentendimento com outros periódicos divulgadores das concepções e ideais republicanos, tal como o periódico O Colombo, com o qual trocava farpas em suas publicações questionando-o em afirmando não saber "em que grande república ou republiqueta a mulher deixe de ser escrava, e goze de direitos políticos, como o de votar e ser votada" (O SEXO FEMININO, 1873, n 15, p. 3). Outro aspecto marcadamente político é a data escolhida para o lançamento do periódico - 07 de setembro. A data além de marcar a posição de D. Francisca Senhorinha, que acreditava na liberdade política do país e de seus cidadãos, ilustrava a grande luta das mulheres pela liberdade feminina.

\footnotetext{
${ }^{8}$ O título da seção é uma citação do periódico - O SEXO FEMININO, 1889, nº 6, p.1.
} 


\section{artigos}

\section{A IMPRENSA FEMININA E A EMANCIPAÇÃO DA MULHER: UMA ANÁLISE DO PERIÓDICO O SEXO FEMININO(RIO DE JANEIRO - 1889}

Nas edições do ano 1889, D. Francisca Senhorinha e suas colaboradoras referem-se e exaltam a família real em duas edições do periódico, com citações recheadas de admiração e respeito. A primeira referência ao Imperador e sua família faz-se presente na edição número 06 do periódico, na qual D. Francisca Senhorinha, fazendo "eco a suas conterrâneas" ${ }^{9}$, publica uma carta a "muito amada Família Real Brasileira"10, na qual se mostra muito agradecida e feliz com a salvação do monarca pelo atentado que sofreu no dia 15 de julho. Nesta passagem, a redatora se mostra bastante satisfeita pelo trabalho daquele que “há quase meio século, sabiamente dirige os destinos do Brasil, fazendo-se amar e respeitar pelos brasileiros e estrangeiros pela igualdade e patriotismo com que dispensa a uns e outros (...)" (O SEXO FEMININO, 1889, n 6, p.1). Outro momento ao qual o periódico recorre à figura do monarca e da Família Real é ao solicitar que invistam em escolas para as meninas, principalmente as carentes, a fim de contribuir para a emancipação intelectual das meninas e mulheres da sociedade brasileira.

Mesmo com sua visível identificação ao governo imperial e com a Família Real, a construção do discurso apresentado pelo periódico flerta também com ideais e discursos republicanos. As edições analisadas neste artigo nos revelam o engajamento de Francisca Diniz ao movimento positivista. Em suas publicações, as redatoras faziam alusão à importância da liberdade não apenas das mulheres, mas no geral. Outro fator bastante presente em seus discursos era o da igualdade, principalmente entre o sexo feminino e o masculino. Igualdade esta que deveria ser aplicada em todas as esferas

\footnotetext{
${ }^{9}$ Excerto do periódico.

${ }^{10}$ Idem.
} 
Karen Menegatt

da sociedade, tanto entre as classes mais abastadas quanto as menos favorecidas, aspecto que deveria ser assegurada pelo Estado e pela Justiça. O posicionamento inabalável do periódico em relação à escravidão também faz coro a esses discursos vinculados pelo republicanismo. Apesar de não explorar a questão da escravidão com muita frequência, Francisca Diniz mostrava sua aversão a esse sistema com firmeza, como podemos notar em sua escrita ao dizer que a escravidão era "um dos maiores crimes do século XIX" (O SEXO FEMININO, 1873, n³ 3, p. 1-2). A redatora utilizava-se da escravidão como metáfora sobre vida das mulheres. Para elas, a escravidão era uma das causas do atraso das civilizações, pois nações escravocratas seriam atrasadas e não poderiam chegar ao progresso.

O ideal de mulher que circulava no periódico parece remeter-se ao imaginário construído pelos republicanos positivistas sobre o que seria a República. De acordo com José Murilo de Carvalho (2011), trata-se de uma figura feminina, maternal, protetora do lar e da família, e que conduziria a nação ao progresso, pois

A república era a forma ideal de organização da pátria. A mulher representava idealmente a humanidade. (...) somente o altruísmo poderia fornecer a base para a convivência social na nova sociedade sem Deus. A mulher era quem meIhor representava esse sentimento (...). (CARVALHO, 2011, p. 81).

A imagem feminina associada à figura materna, vinha na contramão da figura masculina e, de certa forma paterna, associada à monarquia, que representava um monarca protetor, firme, forte e benevolente. A imagem da República como mulher-mãe daria forma à nova pátria, a um novo modo de governo contrário ao autoritarismo do Imperador. A mulher como imagem da República representaria a liberdade e o futuro promissor que a nação alcançaria, contrapondo-se, assim, à realidade vivida no governo monárquico, já que o grande objetivo dos republicanos era atingir o progresso e a liberdade, e estes não seriam encontrados em outro lugar que não fosse na República. 


\section{artigos}

\section{A IMPRENSA FEMININA E A EMANCIPAÇÃO DA MULHER: UMA ANÁLISE DO PERIÓDICO O SEXO FEMININO(RIO DE JANEIRO - 1889}

A apropriação de um discurso associado à vertente republicana nos mostra muito sobre uma das concepções de "mulher" que circulavam no final do século XIX. O sexo feminino seria o responsável pelo progresso e pelo sucesso do lar e da nação, já que além de ser maternal, era altruísta o suficiente para colocar seus filhos (a pátria) em primeiro lugar.

\section{NARRATIVAS E DISCURSOS POR MÃOS FEMININAS}

Serão o homem e a mulher iguais nas manifestações e capacidade de suas faculdades? O sexo feminino apresentará as mesmas vocações, atividade, cultura de inteligência e energia como a do homem? Pela análise e observação destes quesitos provaremos que a mulher não só tem todos os dons concedidos ao homem, como em muitos até o excede com superioridade. (O SEXO FEMININO, $\mathrm{n}^{\circ} 4,1889$, p. 1)

A racional emancipação da mulher, este era o principal objetivo pelo qual D. Francisca Senhorinha da Motta Diniz e suas colaboradoras que escreviam no periódico $O$ Sexo Feminino lutavam. Na primeira publicação de 1889, o periódico traz o convite para que todas as senhoras que acompanhavam os textos publicados no jornal se juntassem à luta pelas reivindicações dos direitos da mulher, pois o século XIX é "o século das luzes e o da batalha da civilização" (O SEXO FEMININO, 1889, n 1, p. 01) e a emancipação da mulher não pode abster-se dessa arena de lutas. Então, para acompanhar a sociedade moderna e a época das luzes, o papel da mulher deixa de ser apenas o de senhora do lar e símbolo da beleza, e passa a ser de fundamental importância para o desenvolvimento da sociedade, como ilustra o periódico: “A sociedade moderna não educa a mulher exclusivamente para glória e ornamento dos salões, educa-a para ser útil a si e a humanidade". (O SEXO FEMININO, 1889, n 1, p. 01). 


\section{artigos}

Karen Menegatt

Em 1949, Simone de Beauvoir vai dizer que a mulher "reflete uma situação que depende da estrutura da sociedade, estrutura que traduz o grau de evolução técnica a que chegou a humanidade" (BEAUVOIR, p. 83, 2016), mas, já em 1889, as redatoras do periódico defendiam a ideia de que a situação feminina determinava o grau de evolução de um povo, antecipando em mais de meio século as elaborações da filósofa francesa. Para elas, em uma cultura na qual as mulheres eram livres, emancipadas, e participativas na comunidade, como no trabalho e na política, a sociedade seria desenvolvida, bem dirigida e a inteligência seria o patrimônio sagrado. Já em uma cultura na qual as mulheres fossem submissas, escravas, inferiorizadas e discriminadas, a sociedade em consequência era atrasada, indigna, infeliz e não chegaria ao progresso.

Mas de que forma chegar a emancipação? As contribuintes de O Sexo Feminino argumentavam que o caminho para a emancipação da mulher seria a instrução e a participação feminina nas ciências, pois já haveria provas suficientes de que as mulheres tinham a mesma capacidade que os homens para participarem da produção científica, "capacidade essa até superior" (O SEXO FEMININO, 1889, n4, p.01), como D. Francisca Senhorinha gostava de argumentar em tom de deboche ao sexo oposto. Simone de Beauvoir dirá que a emancipação feminina aconteceria apenas a partir da participação das mulheres no trabalho e na exaltação da classe trabalhadora, o que de certa forma já era argumentado pelas redatoras do periódico, pois para elas, era de fundamental importância que o sexo feminino tivesse seu espaço no universo do trabalho, para que dessa forma não precisasse depender financeiramente e intelectualmente do sexo masculino e assim tivesse sua independência (O SEXO FEMININO, 1889, nº 8, p. 01).

De acordo com Nascimento (2004), uma nova configuração do ser mulher vinha sendo criada e estabelecida desde os séculos anteriores. Porém, em meados do século XIX, essa configuração viria a se estabelecer, essa nova estrutura apresentava a mulher 


\section{artigos}

\section{A IMPRENSA FEMININA E A EMANCIPAÇÃO DA MULHER: UMA ANÁLISE DO PERIÓDICO O SEXO FEMININO(RIO DE JANEIRO - 1889}

ligada diretamente a figura da mãe/dona de casa, o que resultaria em um tipo de educação própria para as mulheres que enfatizava o ser uma boa mãe, uma boa dona de casa e uma boa esposa. As redatoras de O Sexo Feminino pareciam aproveitar-se desse discurso para promover a emancipação racional da mulher a partir da educação, de forma a argumentar que se as mulheres fossem bem instruídas, poderiam educar e zelar por seus filhos da melhor forma possível, assim como conduziriam suas casas de forma excepcional, considerando que a sociedade era uma reprodução do lar, ou seja, uma casa bem guiada e organizada resultaria em uma sociedade bem conduzida e progressista. Esse discurso parecia ser uma ferramenta primordial porque, além da identificação feminina, conquistar o apoio dos homens às causas defendidas pelo Jornal era de fato uma das estratégias políticas daquelas intelectuais. O processo de identificação da mulher como mãe, filha e esposa seria uma forma de conquistar a simpatia masculina para suas pautas.

Em um contexto de constantes disputas políticas, no qual os republicanos ganhavam maior espaço com seu discurso de progresso para a sociedade brasileira, a ideia de maior participação da mulher de forma consciente e constante na sociedade angariava cada vez mais forma,

O Sexo Feminino propalava a mulher que teria como base o trinômio: religião, instrução e nação. A construção da mulher e do país aparece como indissociadas; através de uma intervenção ilustrada, alcançar-se-ia a sociedade desejada. Apropriando-se de tal idealização, por vias da retórica do patriotismo e do desejo do progresso, O Sexo Feminino emula a mulher civilizada e instruída, interventora na dinâmica social. (NASCIMENTO, 2004, p. 32)

A participação ativa, emancipada e racional da mulher na sociedade, além de ser fundamental para a condução do lar, seria indispensável para a formação de uma nação que almeja o progresso. Pode-se notar que, a posição do periódico diz respeito a 
Karen Menegatt

uma sociedade que projetava o desenvolvimento, consequentemente levando a emancipação feminina, o que aconteceria através da educação.

Em Breve História do Feminismo no Brasil, Maria Amélia Teles discorre sobre as reivindicações das mulheres durante o período Imperial. Segundo a autora, o ensino proposto para as mulheres na primeira metade do século XIX previa apenas o $1^{\circ}$ grau, o que tornava impossível que as mulheres atingissem níveis de educação mais elevados, e que eram destinados apenas aos homens. A instrução feminina era focada no lar, ou seja, trabalhos com agulha; já a escrita, leitura e cálculos não participavam do universo educacional feminino. As escolas destinadas às meninas existiam em um número muito inferior em relação as destinadas para os meninos. A partir da metade do século, e com o fortalecimento de movimentos políticos como o republicanismo, as mulheres começaram a assumir papéis de contestação a algumas ideias impostas. Escolas destinadas as meninas começam a ser criadas por mulheres, reivindicações por participação na sociedade começam a ser impostas, e o periódico O Sexo Feminino, nesse contexto, aliou-se a essas reivindicações, principalmente pela educação das muIheres e sua emancipação e pela criação de escolas para meninas, de forma que os níveis de escolarização fossem ampliados para as mulheres.

A intenção doutrinária de Francisca Diniz era, primordialmente, a educação da
mulher. Folha por folha, página por página, em todos os exemplares publicados,
a educação feminina pode ser entendida como a condição para qualquer trans-
formação social. Por vezes, essa luta esteve expressa em discursos que denun-
ciavam a realidade brasileira e seu descaso com a instrução feminina; expressa
na realidade de outros países, mais avançados e civilizados, que cuidavam da
educação de seu povo; expressa em artigos que continham projetos pedagógi-
cos que definiam a profissão de professor; na citação de exemplos vitoriosos de
mulheres que obtivera diplomas, lutaram pelo voto ou tornaram-se escritoras;
nos poemas e artigos traduzidos. (ANDRADE, 2006, p. 49-50) Um exemplo de denúncia da realidade brasileira em comparação a "outros países, mais avançados e civilizados, que cuidavam da educação de seu povo" (ANDRADE, 2006, p. 49) pode ser visto na edição número cinco do periódico, quando Francisca 


\section{artigos}

\section{A IMPRENSA FEMININA E A EMANCIPAÇÃO DA MULHER: UMA ANÁLISE DO PERIÓDICO O SEXO FEMININO(RIO DE JANEIRO - 1889}

Senhorinha diz que em alguns lugares da Europa, as mulheres se uniram para abrir estabelecimentos que cuidassem da educação das jovens, e dessa forma, convida as senhoras brasileiras a se organizarem por meio de doações para fundarem casas de educação destinadas a acolherem jovens pobres que não possuíssem condições de pagar por uma escola (O SEXO FEMININO, 1889, n05, p.02). Na edição número nove, Francisca Diniz retoma seu pedido para que fossem abertas casas escolares que acoIhessem meninas pobres desde os 03 anos até que atingissem idade o suficiente para que pudessem se sustentar a partir de sua educação e de seu próprio trabalho. (O SEXO FEMININO, 1889, nº9, p. 2). É notável que a preocupação de Francisca Diniz com a educação das mulheres não se restringia à camada mais abastada da sociedade, mas também, às jovens de origem humilde.

Somos capazes de constatar uma "citação de exemplos vitoriosos de mulheres que obtiveram diplomas" (ANDRADE, 2006, p. 50) na edição número três do periódico em um artigo intitulado Senhoras Advogadas, no qual ela diz que “(...) a recente formatura em Direito de duas Senhoras na faculdade de Recife tem tirado o sono aos Advogados." (O SEXO FEMININO, 1889, n³, p. 4). O artigo em questão versa sobre a discussão que o Instituto da Ordem dos Advogados do Brasil viria a ter sobre a possibilidade da mulher graduada em Direito poder vir a exercer a profissão de advocacia e a magistratura. Francisca Senhorinha defende a capacidade das mulheres em praticar a profissão e diz que "não existe lógica mais cerrada e persuasiva do que a feminina" e ainda termina o artigo com uma aviso efusivo destinado ao sexo oposto: “Tremam, portanto, os advogados brasileiros". (O SEXO FEMININO, 1889, n³, p. 4). 


\section{artigos}

Karen Menegatt

Assim como o trabalho e a educação representam dois dos pilares para a emancipação da mulher, o periódico apresenta um terceiro, que é a religião. Em seus artigos pela "racional emancipação da mulher", D. Francisca Senhorinha apresenta a mulher como uma criação de Deus e que, portanto, teria o mesmo status que o homem frente à criação. Ir contra esta afirmação seria como ir contra as leis naturais; leis estas que preveem a harmonia entre o físico, o moral e o intelectual.

Nenhuma fórmula dada pela lei humana fará tornar a natureza separada das necessidades comuns a ambos os sexos; logo, tornar a mulher um ente passivo, dependente absoluto da vontade do homem é torna-la incompleta, é evita-la e ofender a sua dignidade de ser criada por Deus. Assim sendo, vemos que tudo que ofende a dignidade, a igualdade, a moralidade de nossa ações, ofende a lei natural. (O SEXO FEMININO, 1889, $\mathrm{n}^{\circ}$ 7, p. 1)

A emancipação feminina parece ser, sem dúvida, o principal objetivo do periódico, emancipação essa que só poderia ser alcançada através da educação, e por isso, uma das preocupações das contribuintes do jornal era a instrução das meninas carentes, como já foi citado anteriormente. Sem educação e instrução não haveria nem emancipação, nem progresso, e por tanto, estas deveriam estar ao alcance de todas as mulheres independente da classe e desde cedo, para que assim, as mulheres tivessem a autonomia e a sabedoria de escolher o próprio futuro.

\subsection{O casamento publicizado pelo sexo feminino}

A discussão sobre o casamento também é enfrentada de modo inovador pelo periódico, pois situa mais uma vez as mulheres no centro de um debate público bastante delicado. A pauta sobre o casamento como mais um pretexto para evidenciar o posicionamento das redatoras do periódico sobre as desigualdades de direitos entre os homens e as mulheres, que para elas, não deveriam existir. O casamento é defendido nos artigos como a união perfeita e completa em uma sociedade que prevê o aperfeiçoamento, e por isso, os dois componentes dessa união deveriam estar em condições 


\section{artigos}

\section{A IMPRENSA FEMININA E A EMANCIPAÇÃO DA MULHER: UMA ANÁLISE DO PERIÓDICO O SEXO FEMININO(RIO DE JANEIRO - 1889}

de igualdade (O SEXO FEMININO, 1889, nº 01, p. 03). Na segunda edição do periódico, Francisca Diniz elucida o objetivo dos artigos O Casamento:

As ideias que temos em vista expender com relação ao casamento trarão luz as nossas conterrâneas e provarão a imprescindível necessidade que temos de emancipar-nos dessa tutela injusta que sobre nós pesa. As ideias expostas não nos afiguram utopias, são antes umas novas manifestações acomodadas aos nossos dias. Sentimos maior dificuldade de circunscrever do que em dilatar a exposição dos variados assuntos, em que só nos é possível tocar ligeiramente em pontos mais graves, isto é, nas mais importantes relações da mulher com a família. Não correremos de braços abertos para as ilusões da utopia e sim para a realidade.

Um ponto de grande impacto debatido na terceira edição do periódico é a questão das acusações de crimes no casamento. A redatora da matéria argumenta que o Ministério Público deveria colocar-se em favor da mulher em caso de crimes cometidos pelo homem no matrimônio, defender a moralidade das famílias, bem como o interesse social promovendo as devidas repressões ao marido. Na edição número seis do periódico, a redatora responsável pela matéria admite que as leis e a justiça eram pouco eficientes em defender os assuntos da mulher e, principalmente, em supervisionar os crimes nos casamentos, e assim, impunha leis medíocres e que não costumavam amparar as mulheres, colocando-as em situação de dependência e submissão a seus cônjuges.

Para Francisca Diniz, as desigualdades entre o homem e a mulher, que colocavam o sexo feminino em situação de inferioridade e dependência do homem dentro da relação matrimonial, tornavam a mulher escrava de seu marido. Dentro da perspectiva da intelectual, a escravidão é sinônimo de atraso e retrocesso. Uma sociedade com escravos é uma sociedade antiquada e ignorante. Promover a igualdade tanto nos direitos 


\section{artigos}

Karen Menegatt

quanto nos deveres em um casamento era a forma de libertar a mulher e fazer com que o lar prosperasse, e por consequência a sociedade.

\section{CONSIDERAÇÕES FINAIS}

A proposta deste trabalho era investigar qual era o discurso sobre a mulher, seu papel na sociedade e suas preocupações, às vésperas da Proclamação da República, a partir da análise do periódico O Sexo Feminino, em suas edições de 1889. Partindo da análise do documento e da leitura do referencial teórico selecionado para a pesquisa, pude constatar que a mulher do século XIX era uma mulher reservada à esfera doméstica, à criação dos filhos e aos cuidados da família, ou pelo menos era essa a concepção de mulher que a sociedade construiu, e queria preservar.

O surgimento de uma imprensa feminina mostrou-se no horizonte da segunda metade do século XIX como um agente importante do debate sobre as definições e papéis da mulher na sociedade. O periódico O Sexo Feminino foi um dos principais a contestar a ordem social estabelecida e reivindicar com categoria e frontalmente os direitos da mulher, direitos esses baseados na emancipação racional feminina e no acesso ao universo do trabalho.

Baseada nos artigos publicados pelo jornal, pude constatar que, para as redatoras do periódico, a educação/instrução seria a principal forma de emancipar as mulheres e conquistar a liberdade. Para elas, a educação seria a principal virtude de uma sociedade e o sexo feminino não poderia deixar de participar desse processo de aprendizagem que levaria ao progresso. Afinal, apenas uma sociedade instruída e que prezasse pela educação feminina poderia evoluir constantemente.

Outro ponto a ser salientado é o da composição discursiva que construía um tipo de mulher universal ao qual todas pudessem olhar, reconhecer-se e unir-se, a fim de 


\section{artigos}

\section{A IMPRENSA FEMININA E A EMANCIPAÇÃO DA MULHER: UMA ANÁLISE DO PERIÓDICO O SEXO FEMININO(RIO DE JANEIRO - 1889}

reivindicarem seus direitos na esfera doméstica e pública. As redatoras do periódico 0 Sexo Feminino mostram que sua concepção de mulher livre, emancipada, instruída, capaz e inteligente deveria ser alcançada por qualquer mulher, seja ela na figura de mãe, trabalhadora ou o que quer que quisesse ser, afinal, as mulheres deveriam ter o poder de escolha.

O matrimônio foi um dos argumentos utilizados para sustentar a ideia de igualdade dos sexos, tão defendida pelas redatoras do periódico. Isso nos mostra que além da determinação por trazer a público um assunto pouco debatido, as redatoras do periódico buscavam fundamentar suas reivindicações em todas as áreas em que estavam envolvidas direta ou indiretamente. Para elas a submissão aos maridos era inaceitável e imprópria para os avanços do lar e, por consequência, da sociedade.

O surgimento de uma rede de imprensa inteiramente feminina nos mostra a emergência de diversas questões que estavam afetando o universo feminino. Interpretar essas questões e os discursos produzidos pelo periódico é de certa forma conhecer a realidade das mulheres que tiveram a coragem de reivindicar um espaço público para se fazerem ouvidas e assim, unir suas vozes as demais mulheres que mesmo timidamente, começavam a assumir espaços que também eram seus. 


\section{artigos}

Karen Menegatt

\section{FONTES}

O Sexo Feminino: semanário dedicado aos interesses da mulher. Rio de Janeiro, RJ: Typ. Lombaerts \& Filho, 1889. Disponível em: <http://bndigital.bn.br/acervo-digital/sexo-feminino/706868>.

Periódico O Sexo Feminino. Campanha, 20 de setembro de 1873. №3. Periódico O Sexo Feminino. Campanha, 20 de dezembro de 1874. Nº 15. Periódico O Sexo Feminino. Rio de Janeiro, 14 de agosto de 1875. № 04. Periódico O Sexo Feminino. Rio de Janeiro, 29 de agosto de 1875. № 05. Periódico O Sexo Feminino. Rio de Janeiro, 02 de junho de 1889. Nº1. Periódico O Sexo Feminino. Rio de Janeiro, 09 de junho de 1889. № 02. Periódico O Sexo Feminino. Rio de Janeiro, 30 de junho de 1889. № 04. Periódico O Sexo Feminino. Rio de Janeiro, 18 de julho de 1889. № 06. Periódico O Sexo Feminino. Rio de Janeiro, 31 de julho de 1889. № 07.

\section{Referências Bibliográficas}

ANDRADE, Fernanda Alina de Almeida. Estratégias e Escritos: Francisca Diniz e o Movimento Feminista no Século XIX (1873/1890). Dissertação (Mestrado em História). Faculdade de Filosofia e Ciências Humanas, Universidade Federal de Minas Gerais. Belo Horizonte, 2006.

BEAUVOIR, Simone de. O Segundo Sexo: fatos e mitos. Rio de Janeiro: Nova Fronteira, 2016.

BUITONI, Dulcília Schroeder. Imprensa Feminina. São Paulo: Editora Ática, 1990.

CARVALHO, José Murilo de. A formação das almas: o imaginário da República no Brasil. São Paulo: Companhia das Letras, 2011. 
A IMPRENSA FEMININA E A EMANCIPAÇÃO DA MULHER: UMA ANÁLISE DO PERIÓDICO O SEXO FEMININO(RIO DE JANEIRO - 1889

CASADEl, Eliza Bachega. A inserção das mulheres no jornalismo e a imprensa alternativa: primeiras experiências do final do século XIX. Revista Altejor, São Paulo, v. 1, n. 3, jan - jun 2011.

DALLASTRA, Débora. Da cozinha à lavanderia: a propaganda como dispositivo de captura dos corpos femininos. Trabalho de Conclusão de Curso. Faculdade de História. Universidade Federal da Fronteira Sul. Erechim, 2019.

DEL PRIORE, Mary. História das mulheres: as vozes do silêncio. In: FREITAS, Marcos Cezar de (org). Historiografia brasileira em perspectiva. São Paulo - Contexto, 2007.

DUARTE, Constância Lima. Imprensa Feminina e feminista no Brasil: Século XIX: dicionário ilustrado. Belo Horizonte: Autêntica Editora, 2017.

Feminismo: uma história a ser contada. In: ARRUDA, Angela; HOLLANDA, Heloisa Buarque de (org). Pensamento feminista brasileiro: formação e conceito. Rio de Janeiro: Bazar do Tempo, 2019.

FERREIRA, Lucia M. A. Representações da sociabilidade feminina na imprensa do século XIX. Revista Fênix, Uberlândia, v. 7, nº 2, 2010.

IMPÉRIO DO BRAZIL. Constituição de 1824. Diário Oficial da República Federativa do Brasil, Art. 179, n 4. Brasília, DF. Disponível em: <http://www.planalto.gov.br/ccivil_03/constituicao/constituicao24.htm>. Acesso: 20 out. 19.

MACHADO, H. F. A atuação da Imprensa do Rio de Janeiro no Império do Brasil. Revista do Instituto Histórico e Geográfico Brasileiro, Rio de Janeiro, v. 448, p. 31-62, 2010.

MUZART, Zahidé Lupinacci. Uma espiada na imprensa das mulheres no século XIX. Estudos Feministas, Florianópolis, volume 11, número 01, p. 225-233, 2003.

NASCIMENTO, Cecília Vieira do. 0 Sexo Feminino em campanha pela emancipação da mulher (1873/1874). Dissertação (Mestrado em Educação) - Faculdade de Educação, Universidade Federal de Minas Gerais. Belo Horizonte, 2004. 


\section{artigos}

Karen Menegatt

NOVAES, Elizabete David. Entre o público e o privado: o papel da mulher nos movimentos sociais e a conquista de direitos no decorrer da História. História e Cultura, Franca, v. 4, n. 3, p. 50-66, dez. 2015.

PERROT, Michelle. Os excluídos da História: operários, mulheres e prisioneiros. Rio de Janeiro: Paz e Terra, 2006.

Mulheres Públicas. São Paulo: Editora UNESP, 1998.

PINTO, Céli Regina Jardim. Uma história do feminismo no Brasil. São Paulo: F. Perseu Abramo, 2003.

RIO DE JANEIRO. Decreto de 13 de maio de 1808, Crêa a Impressão Regia. Diário Oficial da República Federativa do Brasil, Brasília, DF. Disponível em: <http://www.planalto.gov.br/ccivil_03/decreto/historicos/dim/DIM-13-5-1808-3.htm>. Acesso em: 20 out. 19.

TELES, Maria Amélia de Almeida. Breve história do feminismo no Brasil. São Paulo, Brasiliense, 1993.

TELES, Norma. Escritoras, escritas, escrituras. In: DEL PRIORE, Mary. História das muIheres no Brasil. São Paulo, Contexto, 2004.

. Rebeldes, Escritoras, Abolicionistas. In: Revista de História, n 120. São Paulo: USP, jan-jul, p. 73-83, 1989.

WOITOWICZ, Karina Janz. Marcos históricos da inserção das mulheres na imprensa: A conquista da escrita feminina. Jornal Alcar, Porto Alegre, v. 4, p. 1-7, out. 2012. 